\title{
Design of a Digitally Controlled Full-Bridge LLC Resonant Converter
}

\author{
Xinwei Zhang ${ }^{\text {a)}}$, Xueye $\mathrm{Wei}^{\mathrm{b})}$, Xiaodong $\mathrm{Wu}^{\mathrm{c})}$ and Xiaolong $\mathrm{Yu}{ }^{\mathrm{d})}$ \\ School of Electronic and Information Engineering, Beijing Jiao tong University, Beijing 100044, China. \\ a) Corresponding author: 16120278@bjtu.edu.cn \\ b)xywei@bjtu.edu.cn \\ c)16125123@bjtu.edu.cn \\ d)16120274@bjtu.edu.cn
}

\begin{abstract}
In this paper, a digitally controlled full-bridge LLC resonant converter based on DSP is designed. The frequency conversion control method is adopted to keep the output voltage constant and achieve the soft-switching of the switches. In this paper, the modes of operation of the full-bridge LLC resonant converter is introduced. The gain characteristics and impedance characteristics of the full-bridge LLC resonant converter are analyzed in detail, and the circuit parameters are designed. Finally, a digitally controlled full-bridge LLC resonant converter prototype with input of DC $400 \mathrm{~V}$ and output of DC48V/600W is fabricated. The correctness of the design is verified by experiments.
\end{abstract}

Key words: LLC Resonant Converter; Digital Control; FHA; Integrated Magnetic; ZVS.

\section{INTRODUCTION}

The development of power electronics technology is increasingly pursuing high-frequency. The problem is that the switching losses of semiconductor switching devices increase dramatically during high frequency operation. The traditional phase-shifted full-bridge PWM converter can realize the zero-voltage turn-on of the switches, but the secondary-side rectifier diode has the problem of reverse recovery, which is not conducive to the improvement of efficiency [1].

The LLC resonant converters can overcome the shortcomings of phase-shifted full-bridge PWM converters significantly. The LLC resonant soft-switching technology can realize Zero-voltage-switching (ZVS) and zerocurrent-switching (ZCS) among all power MOSFETs and all power diodes in the full load range respectively, solving the reverse recovery problem of the secondary-side rectifier diode, and reducing the switching loss of the converter effectively [2].

The traditional analog control circuit is more complex, requires many components, and has very high requirements on the device characteristics, which greatly limits the increase of the power density of the power supply and the reduction of the power supply cost, making it difficult to implement complicated control algorithms. The digital control is mainly based on high-performance single-chip microcomputers (SCMs) or digital signal processors (DSPs), which can implement complex control algorithms and simplify the design of hardware circuits. It is reliable, stable, and flexible, and have the advantages of flexible control [3].

In this paper, the operational principle of full-bridge LLC resonant converter is studied. The gain characteristics and impedance characteristics of LLC resonant converter are analyzed in detail. The main circuit parameters of the converter are designed. A prototype with an input of DC $400 \mathrm{~V}$ and an output of DC48V/600W was fabricated, using the DSP chip TMS320F28335 from Texas Instruments as the main control chip to detect and process the signal, generate the drive signal of the switches, and implement a control algorithm and the design was verified by experiments. 


\section{FULL-BRIDGE LLC RESONANT CONVERTER}

Fig. 1(a) shows a Full-Bridge LLC converter. The switching bridge generates a square waveform to excite the LLC resonant tank, which will output a resonant sinusoidal current that gets scaled and rectified by the transformer and rectifier circuit, the output capacitor filters the rectified ac current and outputs a DC voltage [4].

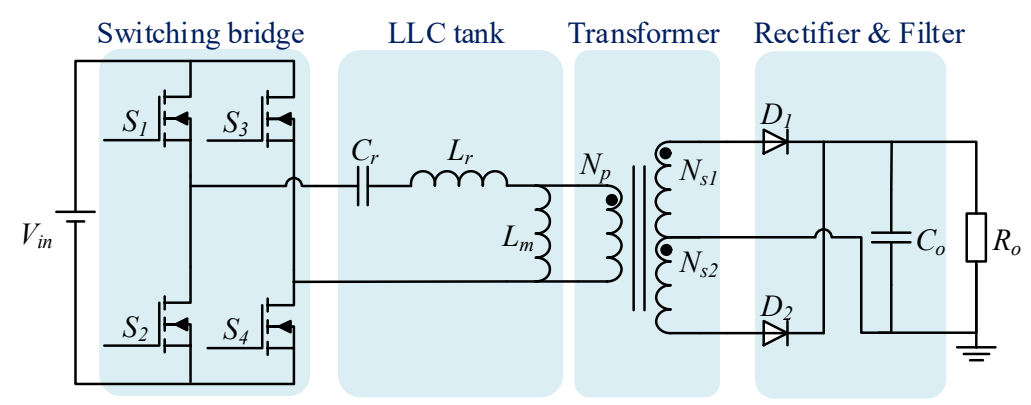

(a)

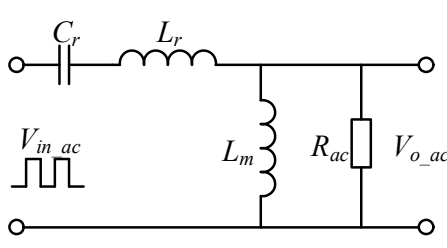

(b)

FIGURE 1. (a) Full-Bridge LLC converter. (b) Equivalent resonant circuit.

The FHA (First Harmonic Analysis) method is used to analyze the full-bridge LLC resonant converter and the equivalent resonant circuit of the converter is obtained [5], as shown in Fig. 1(b). By analyzing the equivalent resonant circuit, the transfer functions of the resonant tank gain and the input impedance can be derived as (1) and (2) respectively.

$$
\begin{gathered}
K\left(Q, h, f_{n}\right)=\left|\frac{V_{o_{-} a c}(s)}{V_{\text {in_ac }_{-}}(s)}\right|=\frac{1}{\sqrt{\left[1+\frac{1}{h}\left(1-\frac{1}{f_{n}^{2}}\right)\right]^{2}+\left[Q\left(f_{n}-\frac{1}{f_{n}}\right)\right]^{2}}} \\
Z_{\text {in }}=Z_{R}\left[\frac{Q h^{2} f_{n}^{2}}{1+Q^{2} h^{2} f_{n}^{2}}+j\left(\frac{h f_{n}}{1+Q^{2} h^{2} f_{n}^{2}}+f_{n}-\frac{1}{f_{n}}\right)\right]
\end{gathered}
$$

Where,

$$
Q=\frac{\sqrt{L_{r} / C_{r}}}{R_{a c}}, R_{a c}=\frac{8 N^{2}}{\pi^{2}} R_{o}, h=\frac{L_{m}}{L_{r}}, f_{n}=\frac{f_{s}}{f_{r}}, f_{r}=\frac{1}{2 \pi \sqrt{L_{r} \cdot C_{r}}}, Z_{R}=\sqrt{\frac{L_{r}}{C_{r}}}
$$




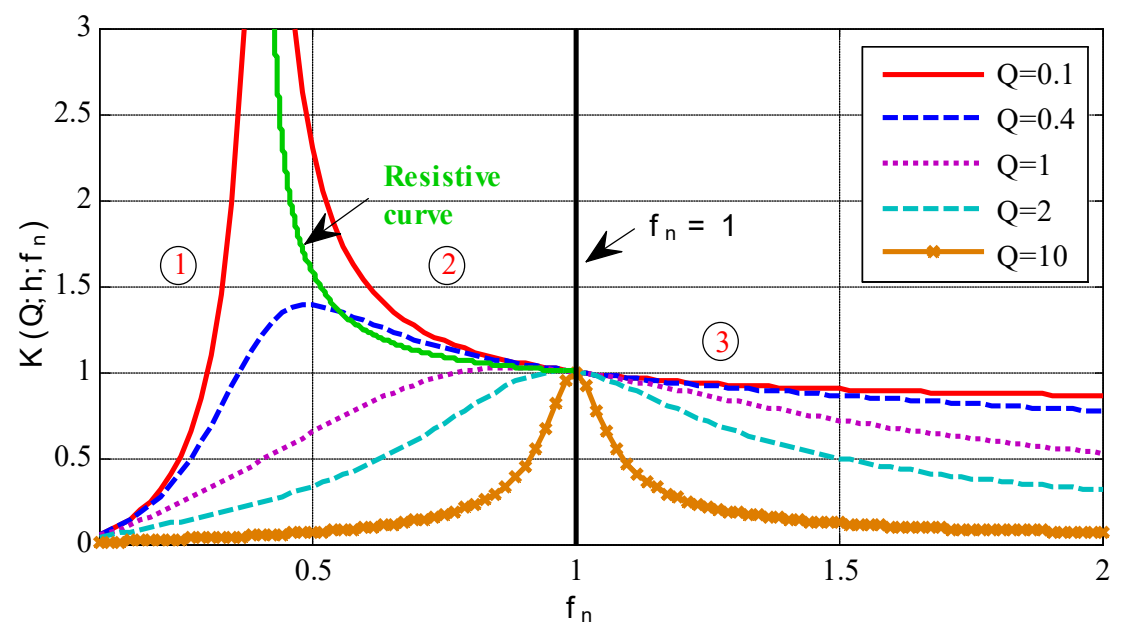

FIGURE 2. Full-bridge LLC resonant converter voltage gain curves and work area division.

Fig. 2 shows the gain characteristics of the LLC resonant converter for different load condition at $\mathrm{h}=5$. It can be seen that all curves have a unity gain at the resonant frequency point. It's also seen from the figure that when $f_{n}$ is determined, the peak gain of the curve decreases with the increase of Q. Therefore, the maximum voltage gain of the converter should be designed under low voltage full load conditions in order to ensure the converter has sufficient voltage gain.

The voltage gain curve when the input impedance of the resonant tank is resistive, divides the converter's operating area into ZCS and ZVS regions. With the line $f_{n}=1$ and the curve, the entire working area of the converter is divided into three parts, as shown in Fig. 2.

Region 1: On the left of the pure resistive curve, the converter operates in the capacitive region and the switches can implement ZCS.

Region 2: Between the line $f_{n}=1$ and the resistive curve, the converter operates in boost mode. The input impedance of the converter is inductive, the switches can implement ZVS, and the rectifier diode can also achieve ZCS.

Region 3: On the right of the line $f_{n}=1$, the converter operates in buck mode. The input impedance of the converter is inductive, the switch can achieve ZVS, but the rectifier diodes have hard commutation.

In this paper, the switches of the converter adopt MOSFET, so the converter should ensure the switch achieves ZVS at any switching frequency. It should also ensure the ZCS of the rectifier diode is realized. Therefore, a fullbridge LLC resonant converter is designed to operate in Region 2 in this paper.

\section{DESIGN OF FULL-BRIDGE LLC RESONANT CONVERTER}

The main design specifications of the full-bridge resonant converter designed in this paper are shown in Table 1.

TABLE 1. Circuit design specifications

\begin{tabular}{ccc}
\hline Symbol & Parameter & Value \\
\hline $\mathrm{V}_{\text {in }} \mathrm{M}_{\mathrm{in}}$ & Minimum input voltage & $270 \mathrm{~V}$ \\
$\mathrm{~V}_{\mathrm{in}} \mathrm{N}_{\mathrm{om}}$ & Rated input voltagedhu & $400 \mathrm{~V}$ \\
$\mathrm{~V}_{\mathrm{in}} \mathrm{M}_{\mathrm{ax}}$ & Maximum input voltage & $420 \mathrm{~V}$ \\
$\mathrm{~V}_{\mathrm{o}}$ & Output voltage & $48 \mathrm{~V}$ \\
$\mathrm{P}_{\mathrm{o}}$ & Output Power & $600 \mathrm{~W}$ \\
$\mathrm{f}_{\mathrm{r}}$ & Resonant frequency & $100 \mathrm{kHz}$ \\
\hline
\end{tabular}

Considering the on-state voltage drop of the rectifier diode, the transformer's theoretical ratio can be given by 


$$
n=\frac{V_{\text {inNom }}}{V_{o}+V_{d}}
$$

The minimum and maximum voltage gain of the converter can be calculated by the following equations.

$$
G_{\min }=n \frac{\left(V_{o}+V_{d}\right)}{V_{\text {inMax }}}, G_{\max }=n \frac{\left(V_{o}+V_{d}\right)}{V_{\text {inMin }}}
$$

The load resistance $\mathrm{R}_{\mathrm{l}}$ and primary equivalent resistance $\mathrm{R}_{\mathrm{ac}}$ can be obtained as follows.

$$
R_{l}=\frac{V_{o}^{2}}{P_{o}}, R_{a c}=n^{2} \frac{8}{\pi^{2}} R_{l}
$$

According to the engineering design experience, the quality factor Q required for the converter generally has a 5\% margin on the basis of the maximum quality factor to prevent the converter from entering the capacitive region when operating near the lowest frequency. The quality factor is then determined by the following equation, where the inductance ratio coefficient $\mathrm{h}$ is usually taken as $2 \sim 6$. In this paper, $\mathrm{h}=5$.

$$
Q=\frac{0.95}{h G_{\max }} \sqrt{h+\frac{G_{\max }^{2}}{G_{\max }^{2}-1}}
$$

Under the premise of meeting the rated output voltage within the input voltage range, the operating frequency range of the converter can be calculated by the following equations.

$$
f_{s \min }=\frac{f_{r}}{\sqrt{1+h\left(1-\frac{1}{G_{\max }^{2}}\right)}}, f_{s \max }=\frac{f_{r}}{\sqrt{1+h\left(1-\frac{1}{G_{\min }}\right)}}
$$

Knowing $\mathrm{Q}$ and $\mathrm{R}_{\mathrm{ac}}$, the resonant tank's component parameters can be obtained by the following formulas.

$$
C_{\mathrm{r}}=\frac{1}{2 \pi f_{r} R_{a c} Q}, L_{r}=\frac{Q R_{a c}}{2 \pi f_{r}}, L_{m}=h L_{r}
$$

The structure of magnetically integrated transformer is adopted in this paper. Integrated magnetic design aims to integrate all magnetic components present in the circuit in one structure [6]. In this case integrated transformer structure reduces the magnetic components required by utilizing the transformer leakage inductance as resonant inductor and magnetizing inductance as shunt inductor. $\mathrm{L}_{\mathrm{m}}$ and $\mathrm{L}_{\mathrm{r}}$ can be measured in the primary side with the secondary side open circuited and short circuited respectively [7].In order to have sufficient leakage inductance, this paper uses the retaining wall to separate the primary and secondary windings of the transformer, and the leakage inductance can be adjusted by adjusting the thickness of the retaining wall. Magnetizing inductance can be adjusted by simply adjusting the air-gap.

Considering the effect of transformer secondary leakage inductance on voltage gain, the actual transformer turnsratio can be calculated from the following equation.

$$
n_{\text {real }}=n \sqrt{\frac{L_{r}+L_{m}}{L_{m}}}=n \sqrt{\frac{h+1}{h}}
$$


Minimum number of primary turns can be calculated by the following equations, and $\mathrm{Np}$ is chosen so that $\mathrm{Np}>\mathrm{N}_{\mathrm{pmin}}$. In order to reduce the error, the number of secondary turn can be selected first, and the actual number of primary turn can be determined inversely based on the actual turn-ratio.

$$
N_{p \min }=\frac{n_{\text {real }}\left(V_{o}+V_{d}\right)}{2 f_{s \min } \Delta B A_{e}}
$$

Where, $\Delta \mathrm{B}$ - magnetic flux density; $\mathrm{A}_{\mathrm{e}}-$ the effective core area; $\mathrm{f}_{\mathrm{smin}}-$ min switching frequency

TABLE 2. Design parameters

\begin{tabular}{ccc}
\hline Symbol & Parameter & Value \\
\hline $\mathrm{G}_{\mathrm{Min}}$ & Minimum voltage gain & 0.95 \\
$\mathrm{G}_{\mathrm{Max}}$ & Maximum voltage gain & 1.48 \\
$\mathrm{R}_{\mathrm{ac}}$ & Primary equivalent resistance & $210 \Omega$ \\
$Q$ & Quality factor & 0.34 \\
$\mathrm{f}_{\mathrm{s}}$ & Switching frequency range & $51.8 \sim 115.5 \mathrm{kHz}$ \\
$L_{r}$ & Resonant inductor & $112 \mu \mathrm{H}$ \\
$\mathrm{L}_{\mathrm{m}}$ & Magnetizing inductor & $560 \mu \mathrm{H}$ \\
$C_{r}$ & Resonant capacitor & $22.6 \mathrm{nF}$ \\
\hline
\end{tabular}

Considering the ZVS condition and input voltage range, the design parameters of the LLC converter are shown in Table 2.

\section{EXPERIMENTAL RESULTS}

The key components used in the full-bridge LLC resonant converter are shown in Table 3. The specifications of the converter manufactured with the above key components are $\mathrm{Po}=600 \mathrm{~W}$, Vin $=400 \mathrm{~V}, \mathrm{Vo}=48 \mathrm{~V}$. The input of the converter is the output of the PFC converter.

TABLE 3. Key components of the prototype converters

\begin{tabular}{cc}
\hline Symbol & Parameter \\
\hline Main switch & IPP50R190CE \\
Diode & MUR3020WT \\
Transformer core & EE55 \\
Magnetizing inductance & $560 \mu \mathrm{H}$ \\
Leakage/ Resonant inductance & $115 \mu \mathrm{H}$ \\
Resonant capacitor & $22 \mathrm{nF}$ \\
Output capacitor & $470 \mu \mathrm{F}^{*} 2$ \\
Transformer wire (primary) & $0.1 \mathrm{~mm}^{*} 90$ \\
Transformer wire (secondary) & $0.1 \mathrm{~mm}^{*} 200$ \\
Turns-ratio & $N_{p}: N s 1: N s 2=27: 3: 3$ \\
\hline
\end{tabular}



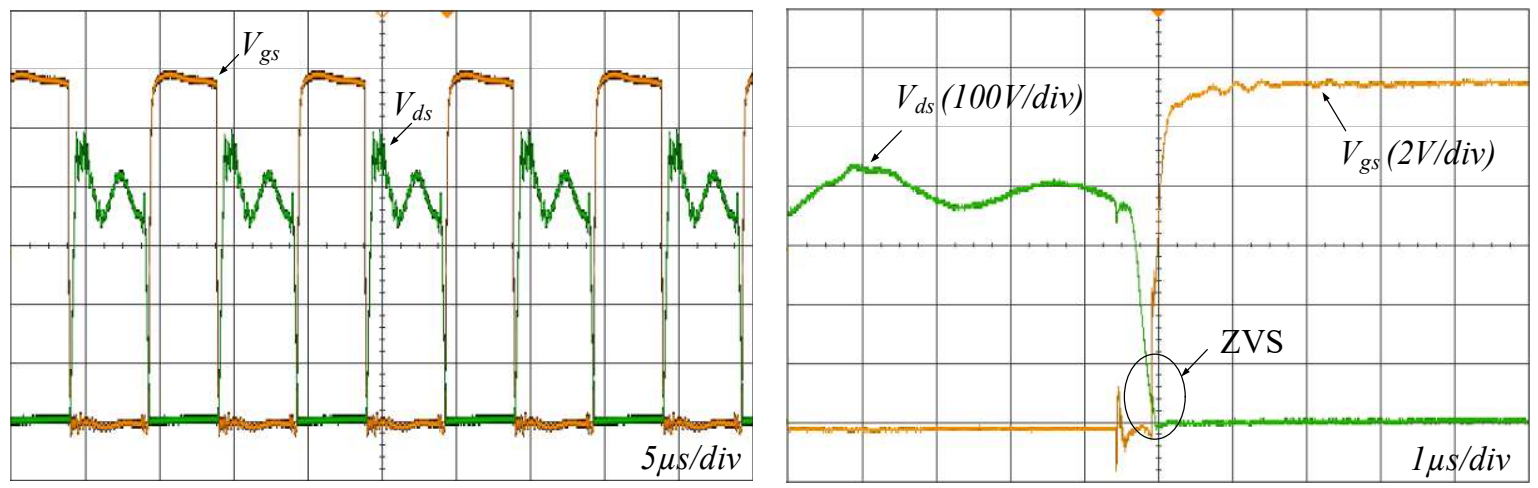

FIGURE 3. (a) The steady state waveform of Vgs and Vds. (b) Details of Vgs and Vds.
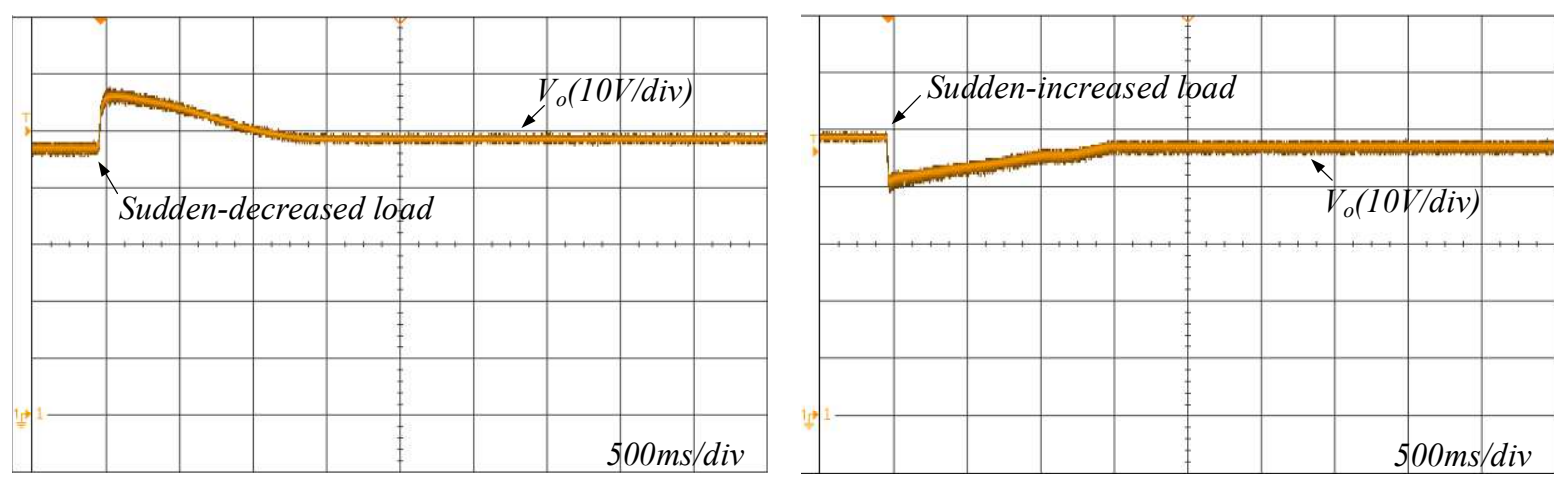

FIGURE 4. (a) The waveform of Vo when load is suddenly decreased. (b) The waveform of Vo when load is suddenly increased.

The full-bridge LLC resonant converter can realize the ZVS turn-on of the primary switch. Fig. 3 shows the steady state waveform of gate voltage Vgs and drain-source voltage Vds of S2. It can be seen that before the switch is turned on, the magnitude of Vds of the S2 has been reduced from about $400 \mathrm{~V}$ to $0 \mathrm{~V}$, enabling zero-voltage turn-on of the switch and eliminating the opening loss.

Fig. 4 shows the output voltage change waveform when the load suddenly increases and suddenly decreases. It can be seen that the output voltage can be kept constant by frequency modulation when the load changes.

\section{CONCLUSION}

In this paper, a digitally controlled full-bridge LLC resonant converter based on DSP is discussed and the design procedure also presented. Prototype of the designed LLC resonant converter is realized. The frequency conversion control method is adopted to keep the output voltage constant and achieve the soft-switching of the switches. The use of magnetic integrated transformers reduces the number of magnetic components required.

\section{ACKNOWLEDGMENTS}

Xinwei Zhang, was born in 1994, Hebei, pursuing for a master's degree in school of Electronic and Information Engineering of Beijing Jiaotong University, the main direction of research are power electronics technology, power supply and on-board Charger. Xueye Wei, was born in 1963, Shandong, Professor of Beijing Jiaotong University, the main research interests include the control of new energy science and technology, control theory and control engineering, power electronics technology, networking technology and application, digital signal processing. Xiaodong Wu, was born in 1994, Shandong, pursuing for a master's degree in school of Electronic and Information Engineering of Beijing Jiaotong University, the main direction of research are power electronics technology and power supply. Xiaolong Yu, was born in 1995, Guizhou, studying for a master's degree in school of Electronic and 
Information Engineering of Beijing Jiaotong University, the main direction of research are optical decay detection and thermal technology.

\section{REFERENCES}

1. D. S. Gautam, F. Musavi, M. Edington, W. Eberle and W. G. Dunford, "An Automotive Onboard 3.3-kW Battery Charger for PHEV Application," in IEEE Transactions on Vehicular Technology, vol. 61, no. 8, pp. 3466-3474, (2012).

2. Bo Yang, F. C. Lee, A. J. Zhang and Guisong Huang, "LLC resonant converter for front end DC/DC conversion," APEC. Seventeenth Annual IEEE Applied Power Electronics Conference and Exposition, (Dallas, TX, 2002), pp. 1108-1112 vol.2.

3. H. Matsuo, Y. Mimura, Y. Nakao, F. Kurokawa and M. Sasaki, "Novel digital controller for the PWM and/or PFM controlled switching DC-DC converters," INTELEC - Twentieth International Telecommunications Energy Conference, (San Francisco, CA, 1998), pp. 225-230.

4. Infineon Technologies, "Resonant LLC Converter: Operation and Design, " V1.0 (September 2012).

5. H. Huang, "FHA-based voltage gain function with harmonic compensation for LLC resonant converter," 2010 Twenty-Fifth Annual IEEE Applied Power Electronics Conference and Exposition (APEC), (Palm Springs, CA, 2010), pp. 1770-1777.

6. Lokesha M H and S. G. Srivani, "LLC resonant converter design and development," 2014 Annual IEEE India Conference (INDICON), (Pune, 2014), pp. 1-5.

7. Bo Yang, Rengang Chen and F. C. Lee, "Integrated magnetic for LLC resonant converter," APEC. Seventeenth Annual IEEE Applied Power Electronics Conference and Exposition, (Dallas, TX, 2002), pp. 346-351 vol.1. 